\title{
On Modeling and Constrained Model Predictive Control of Open Irrigation Canals
}

\author{
Lihui Cen, ${ }^{1}$ Ziqiang Wu, ${ }^{1}$ Xiaofang Chen, ${ }^{1}$ Yanggui Zou, ${ }^{1}$ and Shaohui Zhang ${ }^{2}$ \\ ${ }^{1}$ School of Information Science and Engineering, Central South University, Changsha, Hunan 410083, China \\ ${ }^{2}$ State Key Laboratory of Simulation and Regulation of Water Cycle in River Basin, China Institute of Water Resources and \\ Hydropower Research, Beijing 100038, China \\ Correspondence should be addressed to Xiaofang Chen; xiaofangchen@csu.edu.cn
}

Received 23 September 2016; Revised 8 December 2016; Accepted 22 December 2016; Published 14 February 2017

Academic Editor: Defeng He

Copyright (C) 2017 Lihui Cen et al. This is an open access article distributed under the Creative Commons Attribution License, which permits unrestricted use, distribution, and reproduction in any medium, provided the original work is properly cited.

\begin{abstract}
This paper proposes a model predictive control of open irrigation canals with constraints. The Saint-Venant equations are widely used in hydraulics to model an open canal. As a set of hyperbolic partial differential equations, they are not solved explicitly and difficult to design optimal control algorithms. In this work, a prediction model of an open canal is developed by discretizing the Saint-Venant equations in both space and time. Based on the prediction model, a constrained model predictive control was firstly investigated for the case of one single-pool canal and then generalized to the case of a cascaded canal with multipools. The hydraulic software SICC was used to simulate the canal and test the algorithms with application to a real-world irrigation canal of Yehe irrigation area located in Hebei province.
\end{abstract}

\section{Introduction}

Open irrigation canals deliver water from the water sources to the farmlands to satisfy the irrigation demands. With the scarcity of water resources, better water control and management attracts increasing attention in both the mathematical and engineering communities. Open irrigation canals are well modeled by the Saint-Venant equations, a set of hyperbolic partial differential equations. The control problem of irrigation canals could be stated as that the water level and water flow rate in a canal are regulated by using the gate opening heights as control actions.

The control problem has been investigated in the last few decades. Boundary control of open canals indicates the stable boundary feedback control laws proposed directly based on the Saint-Venant equations. The boundary feedback control was proposed to guarantee the stability of the solutions of the Saint-Venant equations by using either a Riemann invariants approach $[1,2]$ or a Lyapunov approach $[3,4]$. On the other hand, based on the simplified model derived either from the Saint-Venant equations or from the mass conservation laws, a large number of control methods have been proposed ranging from the simplest to the most sophisticated. They were classified in the survey paper [5].

Advanced control policies like model predictive control are becoming a research focus in recent years. According to the strength of the rainfall-runoff, multiple model predictive control of a drainage canal is presented [6]. Distributed model predictive control and coordinated policy for an irrigation canal were presented by dividing the multipool canal into several subsystems according to the local structures with communications among the subsystems $[7,8]$. A two-level hierarchical distributed model predictive control with a risk management strategy was proposed based on a simplified model coming from the flow conservation law [9]. A constrained predictive control was presented based on an ARIMA model of an irrigation canal [10]. A nonlinear predictive control based on Saint-Venant equations was presented to regulate both water depth and water flow rate by solving the two-point boundary value problem numerically [11]. A multivariable model predictive controller was discussed and tested on a laboratory canal [12].

In this work, an approximated predictive model derived from the Saint-Venant equations by discretization in both 
space and time was presented. Since the gate opening height is constrained by the boundary water depth, a constrained model predictive control was developed to solve the optimization problem. To test the performance of this predictive control algorithm, a numerical model of one singlepool irrigation canal located in Hebei province of China was built in the hydraulic software SICC by using the 1dimensional hydrodynamic model. The control algorithm was tested through the link between MATLAB and SICC. The predictive control algorithm was further extended to a multipool irrigation canal.

\section{Modeling of Open Irrigation Canals}

The dynamics of open irrigation canals are described by the Saint-Venant equations [13]

$$
\begin{array}{r}
\frac{\partial A_{c}}{\partial t}+\frac{\partial Q_{c}}{\partial x}=0 \\
\frac{\partial Q_{c}}{\partial t}+\frac{\partial}{\partial x}\left(\frac{Q_{c}^{2}}{A_{c}}\right)+g A_{c} \frac{\partial H_{c}}{\partial x}+g A_{c}\left(S_{f}-S_{0}\right)=0
\end{array}
$$

where the first equation of (1) is the continuity equation, the second one is the dynamical equation, $t$ is time, $x \in[0, L]$ is the space coordinate with $L$ being the length of the canal, $A_{c}=A_{c}(x, t)$ is the wetted cross section at point $x$ and time $t$, $Q_{c}=Q_{c}(x, t)$ is the water flow rate, $H_{c}=H_{c}(x, t)$ is the water level, $g$ is the gravity acceleration constant, $S_{f}$ is the friction slope, and $S_{0}$ is the bed slope. $S_{f}$ and $S_{0}$ are defined as follows:

$$
\begin{aligned}
S_{f} & =\frac{Q_{c}^{2}}{K_{c}^{2}}, \\
K_{c} & =\frac{A_{c} R_{c}^{2 / 3}}{n_{c}},
\end{aligned}
$$

where $R_{c}$ is the hydraulic radius and $n_{c}$ is the roughness coefficient. Let $B_{c}$ be the bottom width and $Z_{c}$ be the side slope; it follows that $A_{c}=\left(B_{c}+H_{c} Z_{c}\right) H_{c}$.

The discharge relationship of a gate between the gate opening height and the water head is described by

$$
Q_{c}=C_{d} L_{c} U_{c} \sqrt{2 g \Delta H_{c}}
$$

where $C_{d}$ is the discharge coefficient, $L_{c}$ is the gate width, $U_{c}$ is the gate opening height, and $\Delta H_{c}=H_{\text {left }}-H_{\text {right }}$ is the difference between the left and right water levels of the gate.

Let us consider a single-pool canal delimited by two gates [14], as shown in Figure 1. $H_{u}$ and $H_{d}$, the upstream water level of Gate 1 and the downstream water level of Gate 2, are assumed to be two constants. $\Delta H_{u}$ and $\Delta H_{d}$ are the differences between the left and right water levels of Gate 1 and Gate 2, respectively. The water dynamics are modeled by the Saint-Venant equations shown in (1).

Since the Saint-Venant equations are a set of hyperbolic PDEs, it is difficult to build a control scheme for a canal system directly based on them. In order to build a control model of an irrigation canal, the Saint-Venant equations are

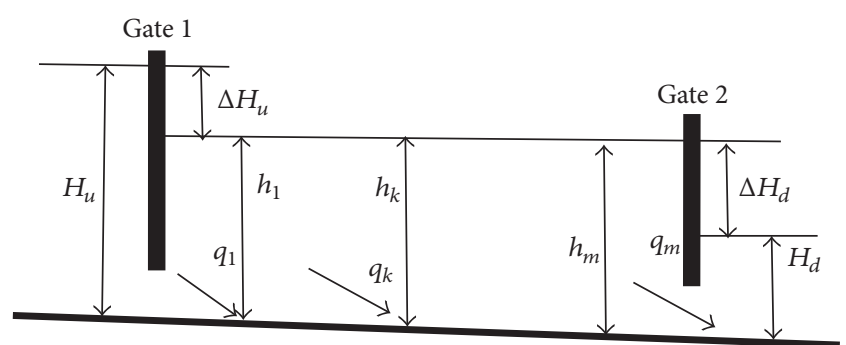

FIGURE 1: Structure of one single-pool canal.

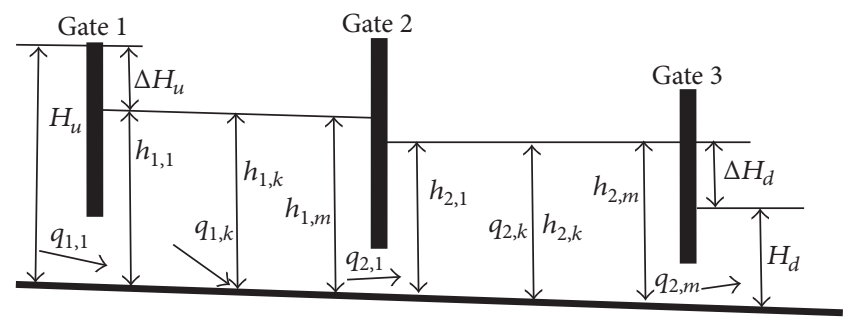

FIGURE 2: Structure of a two-pool cascaded canal.

simplified by using the spatial discretization. In this paper, the pool is divided into $m-1$ sections with $m$ points in space. Define $h_{k}(k=1,2, \ldots, m)$ and $q_{k}(k=1,2, \ldots, m)$ as the water level and flow rate at point $k$ and their equilibrium values as $\bar{H}_{k}(k=1,2, \ldots, m)$ and $\bar{Q}_{k}(k=1,2, \ldots, m)$; then the differences between the actual water level and flow rate and the equilibrium ones at point $k$ could be denoted as $\Delta h_{k}=$ $h_{k}-\bar{H}_{k}(k=1,2, \ldots, m)$ and $\Delta q_{k}=q_{k}-\bar{Q}_{k}(k=1,2, \ldots, m)$. Similarly, define the gate opening heights of the upstream and downstream gates and their corresponding equilibrium values as $u_{1}, u_{2}$ and $\bar{U}_{1}, \bar{U}_{2}$; then the differences between the gate opening heights and their equilibrium points are denoted by $\Delta u_{i}=u_{i}-\bar{U}_{i}(i=1,2)$. By using the finite difference method, the Saint-Venant equations could be discretized in space and then linearized around the equilibrium as follows $[14,15]$ :

$$
\begin{aligned}
& \Delta \dot{x}_{s}=A_{s} \Delta x_{s}+B_{s} \Delta u_{s}, \\
& \Delta y_{s}=C_{s} \Delta x_{s},
\end{aligned}
$$

where the state vector $\Delta x_{s}=\left[\Delta h_{1}, \Delta h_{2}, \Delta q_{2}, \ldots, \Delta h_{k}\right.$, $\left.\Delta q_{k}, \ldots, \Delta h_{m-1}, \Delta q_{m-1}, \Delta h_{m}\right]^{T} \in R^{2 m-2}$, the control vector $\Delta u_{s}=\left[\Delta u_{1}, \Delta u_{2}\right]^{T} \in R^{2}$, and the output vector $\Delta y_{s}=$ $\left[\Delta h_{1}, \ldots, \Delta h_{k}, \ldots, \Delta h_{m}\right]^{T} \in R^{m}$.

In the following, the modeling of a single-pool canal is extended to the cascaded multipool canal. A cascaded multipool canal is composed by $n$ pools joined by $n+1$ gates. Without loss of generalization, a two-pool cascaded irrigation canal is taken as the example, as shown in Figure 2. The irrigation canal consists of two pools delimited by three underflow gates. The water dynamics of each pool are also described by the Saint-Venant equations. 
Following the modeling of a single-pool irrigation canal, the Saint-Venant equations are simplified for pool $i(i=1,2)$ as follows:

$$
\begin{aligned}
& \Delta \dot{x}_{s i}=A_{s i} \Delta x_{s i}+B_{s i} \Delta u_{s i}, \\
& \Delta y_{s i}=C_{s i} \Delta x_{s i},
\end{aligned}
$$

$$
(i=1,2)
$$

where the state vector $\Delta x_{s i}=\left[\Delta h_{i, 1}, \Delta h_{i, 2}, \Delta q_{i, 2}, \ldots, \Delta h_{i, k}\right.$, $\left.\Delta q_{i, k}, \ldots, \Delta h_{i, m-1}, \Delta q_{i, m-1}, \Delta h_{i, m}\right]^{\prime} \in R^{2 m-2},(i=1,2)$, the control vector $\Delta u_{s i}=\left[\Delta u_{i}, \Delta u_{i+1}\right]^{\prime} \in R^{2}(i=1,2)$, and the output vector $\Delta y_{s i}=\left[\Delta h_{i, 1}, \ldots, \Delta h_{i, k}, \ldots, \Delta h_{i, m}\right]^{\prime} \in R^{m},(i=$ $1,2)$.

From (3), the discharge at the intermediate gate is related to the difference between the water level $h_{1, m}$ at the last point $m$ in pool 1 and the water level $h_{2,1}$ at the first point 1 in pool 2 as follows:

$$
q_{2}=C_{d} L_{c 2} U_{c 2} \sqrt{2 g\left(h_{1, m}-h_{2,1}\right)} .
$$

Combining (5) and (6), it follows the mathematical model of the two-pool cascaded irrigation canal derived from the Saint-Venant equations

$$
\begin{aligned}
& \Delta \dot{x}_{d}=A_{d} \Delta x_{d}+B_{d} \Delta u_{d}, \\
& \Delta y_{d}=C_{d} \Delta x_{d},
\end{aligned}
$$

where the state vector $\Delta x_{d}=\left[\Delta h_{1,1}, \Delta h_{1,2}, \Delta q_{1,2}, \ldots, \Delta h_{1, k}\right.$, $\Delta q_{1, k}, \ldots, \Delta h_{1, m-1}, \Delta q_{1, m-1}, \Delta h_{1, m}, \Delta h_{2,1}, \Delta h_{2,2}, \Delta q_{2,2}, \ldots$, $\left.\Delta h_{2, k}, \Delta q_{2, k}, \ldots, \Delta h_{2, m-1}, \Delta q_{2, m-1}, \Delta h_{2, m}\right]^{T} \in R^{4 m-4}$, the control vector $\Delta u_{d}=\left[\Delta u_{1}, \Delta u_{2}, \Delta u_{3}\right]^{T} \in R^{3}$, and the output vector $\Delta y_{d}=\left[\Delta h_{1,1}, \ldots, \Delta h_{1, k}, \ldots, \Delta h_{1, m}, \Delta h_{2,1}, \ldots\right.$, $\left.\Delta h_{2, k}, \ldots, \Delta h_{2, m}\right]^{T} \in R^{2 m}$.

\section{Mathematical Formulation of Constrained Model Predictive Control of Irrigation Canals}

Since the objective is to apply a model predictive control to both the one single-pool canal and the cascaded canal, the model described by (4) should be converted into a discretetime version as follows:

$$
\begin{aligned}
\Delta x_{s}(k+1) & =G_{s} \Delta x_{s}(k)+H_{s} \Delta u_{s}(k), \\
\Delta y_{s}(k) & =C_{s} \Delta x_{s}(k),
\end{aligned}
$$

where $G_{s}, H_{s}$, and $C_{s}$ are the discrete version of matrices $A_{s}$, $B_{s}$, and $C_{s}$.

Since the difference between the actual water level at each spatial point and the target one could be defined as $\Delta y_{s}=$ $y_{s}-\bar{H}$, in which $y_{s}=\left[h_{1}, \ldots, h_{k}, \ldots, h_{m}\right]^{T} \in R^{m}$ and $\bar{H}=$ $\left[\bar{H}_{1}, \ldots, \bar{H}_{k}, \ldots, \bar{H}_{m}\right]^{T} \in R^{m}$, the state equations (4) could be rewritten as

$$
\begin{aligned}
\Delta x_{s}(k+1) & =G_{s} \Delta x_{s}(k)+H_{s} \Delta u_{s}(k), \\
y_{s}(k) & =C_{s} \Delta x_{s}(k)+\bar{H} .
\end{aligned}
$$

Let $\xi x, \xi y$, and $\xi u$ be the increments in terms of the state vector, output vector, and the control vector at the adjacent sampling time; it is given that

$$
\begin{aligned}
\xi x(k+1) & =\Delta x_{s}(k+1)-\Delta x_{s}(k) \\
& =A_{s} \xi x(k)+B_{s} \xi u(k), \\
\xi y(k+1) & =\Delta y_{s}(k+1)-\Delta y_{s}(k) \\
& =C_{s}\left(\Delta x_{s}(k+1)-\Delta x_{s}(k)\right) \\
& =C_{s} \xi x(k+1)=C_{s} A_{s} \xi x(k)+C_{s} B_{s} \xi u(k) .
\end{aligned}
$$

Thus the state-space equations of the one single-pool canal for designing the model predictive control could be written as follows:

$$
\begin{aligned}
{\left[\begin{array}{c}
\xi x(k+1) \\
y_{s}(k+1)
\end{array}\right] } & =\left[\begin{array}{cc}
G_{s} & 0 \\
C_{s} G_{s} & I
\end{array}\right]\left[\begin{array}{l}
\xi x(k) \\
y_{s}(k)
\end{array}\right]+\left[\begin{array}{c}
H_{s} \\
C_{s} H_{s}
\end{array}\right] \xi u(k), \\
y_{s}(k) & =\left[\begin{array}{ll}
0 & I
\end{array}\right]\left[\begin{array}{l}
\xi x(k) \\
y_{s}(k)
\end{array}\right] .
\end{aligned}
$$

The performance functional of the model predictive control problem for the one single-pool canal has the following form:

$$
\begin{aligned}
\min _{\xi U} J(\xi U, t)= & \sum_{j=1}^{M}\left\|y_{s}(k+j \mid k)-r(k+j \mid k)\right\|_{Q}^{2} \\
& +\sum_{j=0}^{N-1}\|\xi u(k+j \mid k)\|_{R}^{2},
\end{aligned}
$$

where $\xi U=[\xi u(k \mid k), \xi u(k+1 \mid k), \ldots, \xi u(k+N-$ $1 \mid k)]^{T}, r(k+j \mid k)$ is the reference trajectory, $M$ is the prediction horizon, $N$ is the control horizon, and $Q$ and $R$ are, respectively, nonnegative and positive definite weighting symmetric matrices with appropriate dimensions.

Considering that the gate opening height must be restricted by the upstream and downstream water levels of the gate, the control actions representing the gate opening heights should be constrained by

$$
\begin{aligned}
& 0 \leq u_{1}(k+j-1 \mid k)<H_{u}, \quad(j=1, \ldots, M), \\
& 0 \leq u_{2}(k+j-1 \mid k)<h_{n}(k+j-1 \mid k),
\end{aligned}
$$$$
(j=1, \ldots, M) \text {. }
$$

Similar to the formulation of model predictive control problem of one single-pool canal, the discrete-time version of (7) for a cascaded multipool irrigation canal has the following form:

$$
\begin{aligned}
\Delta x_{d}(k+1) & =G_{d} \Delta x_{d}(k)+H_{d} \Delta u_{d}(k), \\
\Delta y_{d}(k) & =C_{d} \Delta x_{d}(k) .
\end{aligned}
$$

Substituting $\Delta y_{d}=y_{d}-\bar{H}$ into (15) gives

$$
\begin{aligned}
\Delta x_{d}(k+1) & =G_{d} \Delta x_{d}(k)+H_{d} \Delta u_{d}(k), \\
y_{d}(k) & =C_{d} \Delta x_{d}(k)+\bar{H} .
\end{aligned}
$$


Let $\xi x, \xi y$, and $\xi u$ be the increments in terms of the state vector, output vector, and the control vector at the adjacent sampling time; it is given that

$$
\begin{aligned}
\xi x(k+1) & =\Delta x_{d}(k+1)-\Delta x_{d}(k) \\
& =A_{d} \xi x(k)+B_{d} \xi u(k), \\
\xi y(k+1) & =\Delta y_{d}(k+1)-\Delta y_{d}(k) \\
& =C_{d}\left(\Delta x_{d}(k+1)-\Delta x_{d}(k)\right) \\
& =C_{d} \xi x(k+1) \\
& =C_{d} A_{d} \xi x(k)+C_{d} B_{d} \xi u(k) .
\end{aligned}
$$

Thus the state-space equations of the two-pool cascaded canal for designing the model predictive control could be written as follows:

$$
\begin{aligned}
{\left[\begin{array}{l}
\xi x(k+1) \\
y_{d}(k+1)
\end{array}\right]=} & {\left[\begin{array}{cc}
G_{d} & 0 \\
C_{d} G_{d} & I
\end{array}\right]\left[\begin{array}{l}
\xi x(k) \\
y_{d}(k)
\end{array}\right] } \\
& +\left[\begin{array}{c}
H_{d} \\
C_{d} H_{d}
\end{array}\right] \xi u(k), \\
y_{d}(k)= & {\left[\begin{array}{ll}
0 & I
\end{array}\right]\left[\begin{array}{l}
\xi x(k) \\
y_{d}(k)
\end{array}\right] . }
\end{aligned}
$$

The performance functional of the model predictive control problem for the two-pool cascaded canal has the following form:

$$
\begin{aligned}
\min _{\xi U} J(\xi U)= & \sum_{j=1}^{M}\left\|y_{d}(k+j \mid k)-r(k+j \mid k)\right\|_{Q}^{2} \\
& +\sum_{j=0}^{N-1}\|\xi u(k+j \mid k)\|_{R}^{2} .
\end{aligned}
$$

The control constraints are

$$
\begin{aligned}
& 0 \leq u_{1}(k+j-1 \mid k)<H_{u}, \quad(j=1, \ldots, M), \\
& 0 \leq u_{2}(k+j-1 \mid k)<h_{1, m}(k+j-1 \mid k), \\
& (j=1, \ldots, M), \\
& 0 \leq u_{3}(k+j-1 \mid k)<h_{2, m}(k+j-1 \mid k), \\
& (j=1, \ldots, M) .
\end{aligned}
$$

The control framework of the constrained model predictive control for a two-pool canal is depicted in Figure 3.

\section{Simulation Results and Applications}

4.1. Case of One Single-Pool Canal. In this section, the proposed constrained model predictive control was applied to a single-pool canal. The test canal is part of Yehe irrigation area in Hebei province of China [16], as shown in Figure 4. The canal has a constant rectangular cross section. The

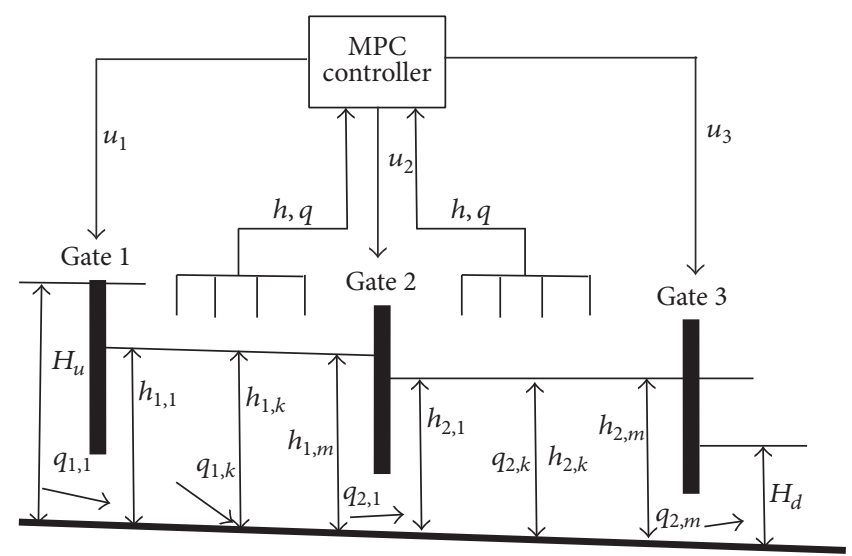

FIGURE 3: Structure of predictive control scheme.

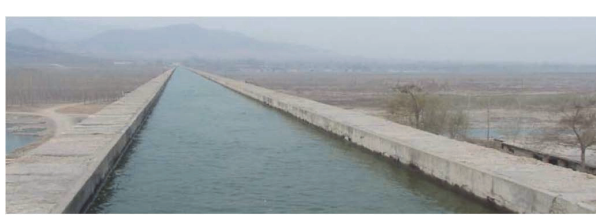

FIGURE 4: A single-pool canal in Yehe irrigation area.

geometric parameters are summarized in Table 1, including the length, bottom width, canal height, bed slope, and side slope. The hydraulic conditions are summarized in Table 2, including the initial discharge at both gates at $t=0$ and the initial water level of the canal at $t=0$.

The simulations are performed on a PC with CORE i5, RAM 4 GB. The working environment is WIN 7 32-bit operation system and MATLAB R2008b.

This one single-pool canal is divided into 3 sections with 4 spatial points. A numerical model of the canal is established in a hydraulic software, SICC (Simulation of Irrigation Canals and Control) developed by Irstea [17]. The constrained predictive controller is applied to the SICC model through the link between SICC and MATLAB. The weighting matrices $Q$ and $R$ are selected as an identity matrix with according dimensions, respectively. The control horizon $N$ and the prediction horizon $M$ are selected to be of the same length; that is, $N=M=6$.

The simulation time is set as 59 minutes. According to the irrigation demands, it is desired that the target water level of the pool is always kept at $r=1.3 \mathrm{~m}$ in whole simulation. The evolutions of the water levels at four spatial points are illustrated in Figure 5. From these figures, the water levels at the last three points have time delays except the first point. The water levels at the 1st and 4th point are stabilized at the target value faster than those at the 2 nd and 3 rd point. At each optimization step, it is observed that the upper bound of the control constraint (14) is varied with respect to the water level at the 4 th spatial point. The evolutions of the two gate opening heights are illustrated in Figure 6. 


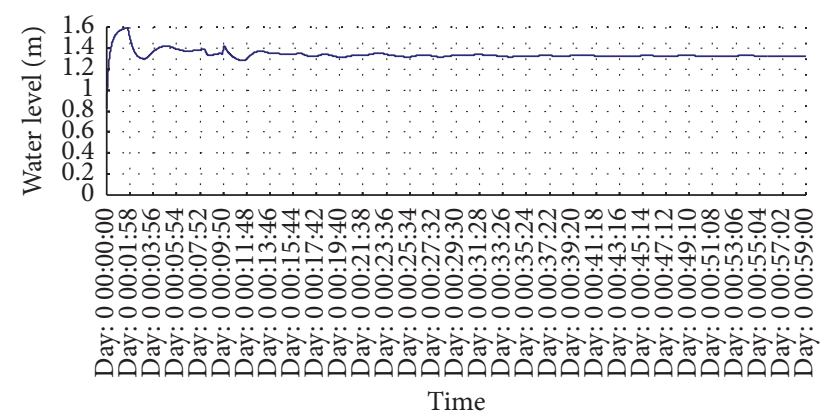

(a) Water level at 1st point

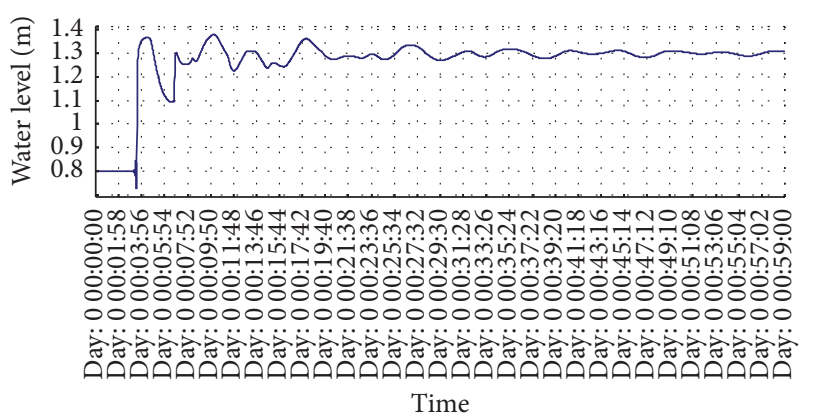

(c) Water level at 3rd point

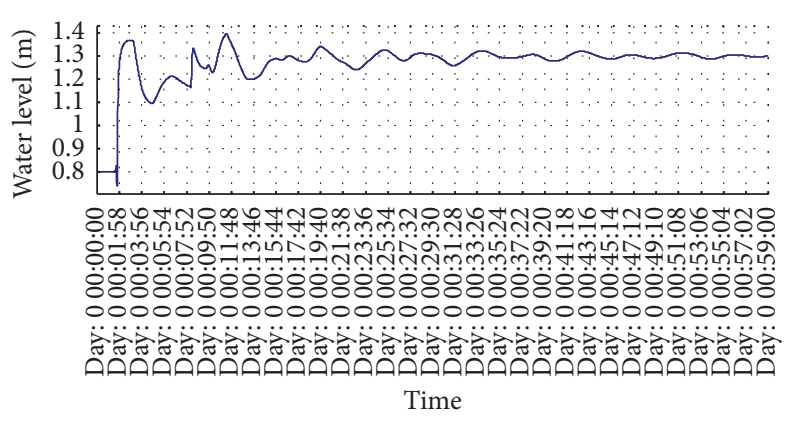

(b) Water level at 2nd point

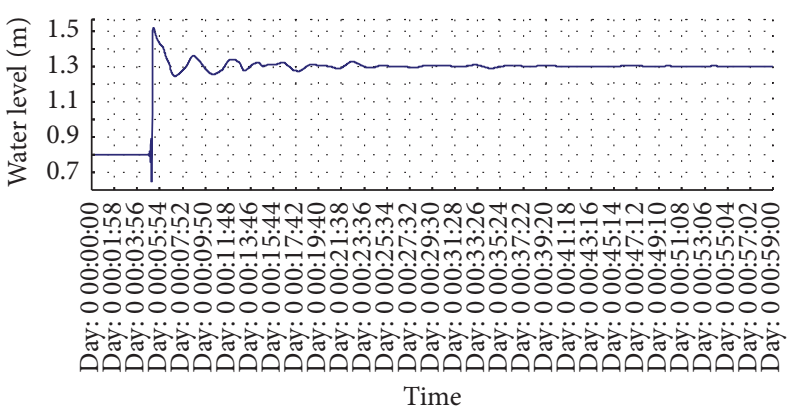

(d) Water level at 4 th point

FIgURE 5: Evolutions of water levels at four points.

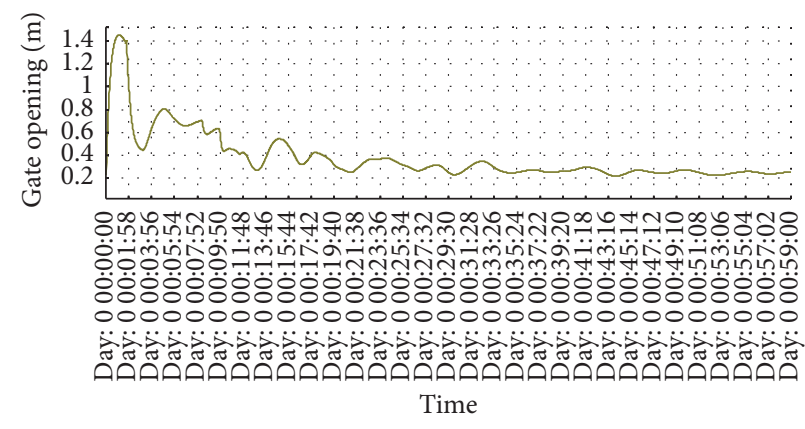

(a) Opening height of Gate 1

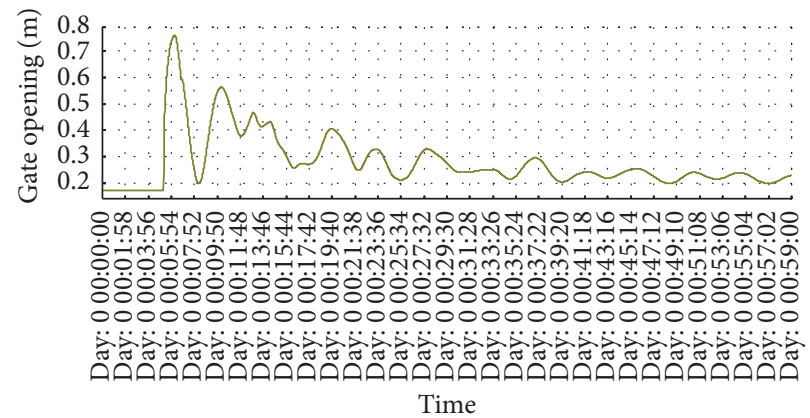

(b) Opening height of Gate 2

FIGURE 6: Evolutions of two gate opening heights.

4.2. Case of a Two-Pool Cascaded Canal. In the case of twopool cascaded canal, two pools are assumed having the same length and with a constant trapezoidal cross section, as shown in Figure 7. The geometric parameters and hydraulic conditions of each pool are listed in Tables 3 and 4, respectively. Each pool is also divided into 3 sections with 4 points. The control horizon and prediction horizon take the same as those taken in the one single-pool case. By using SICC and MATLAB, the constrained model predictive controller is tested.

The simulation time is set as $300 \mathrm{~s}$. Before $100 \mathrm{~s}$, the target water levels of two pools are set as $r_{1}(t)=2.5 \mathrm{~m}$ and $r_{2}(t)=$ $2 \mathrm{~m}$. After $100 \mathrm{~s}$, the target water levels of two pools switch to $r_{1}(t)=2 \mathrm{~m}$ and $r_{2}(t)=1.5 \mathrm{~m}$. Similar to the case of one single-pool canal, the first scenario about control horizon and prediction horizon is selected as $N=M=10$.

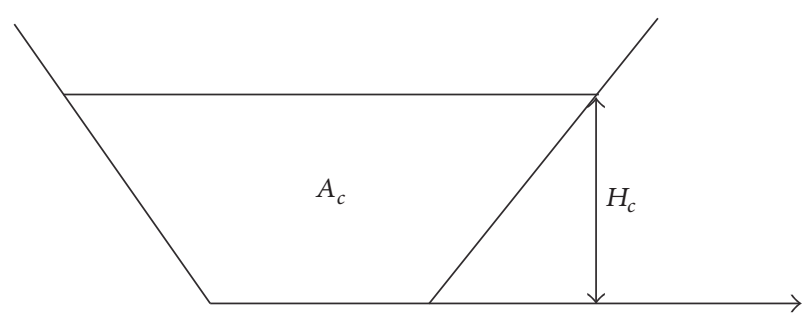

FIGURE 7: Schematic of a constant trapezoidal cross section.

The simulation results run by SICC about the water level at each spatial point in each pool and the gate opening heights are shown in Figures 8, 9, and 10. The evolutions of water levels at four points in pool 1 and pool 2 are illustrated in 


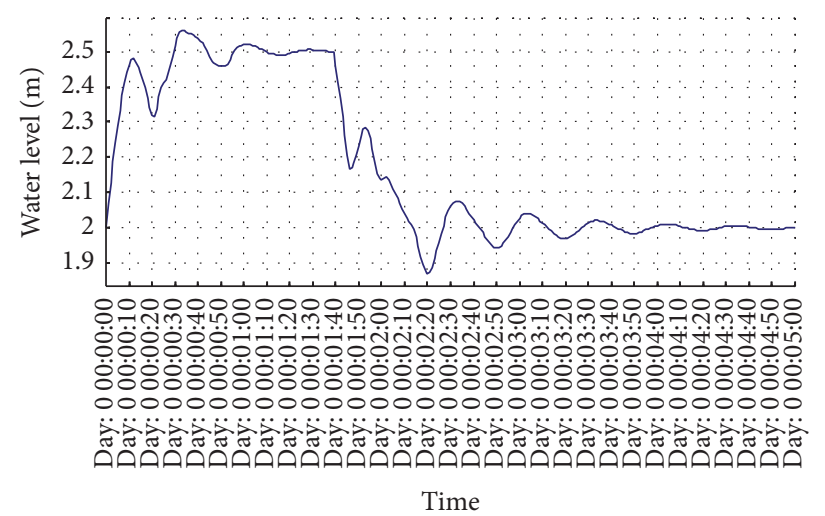

(a) Water level at 1st point

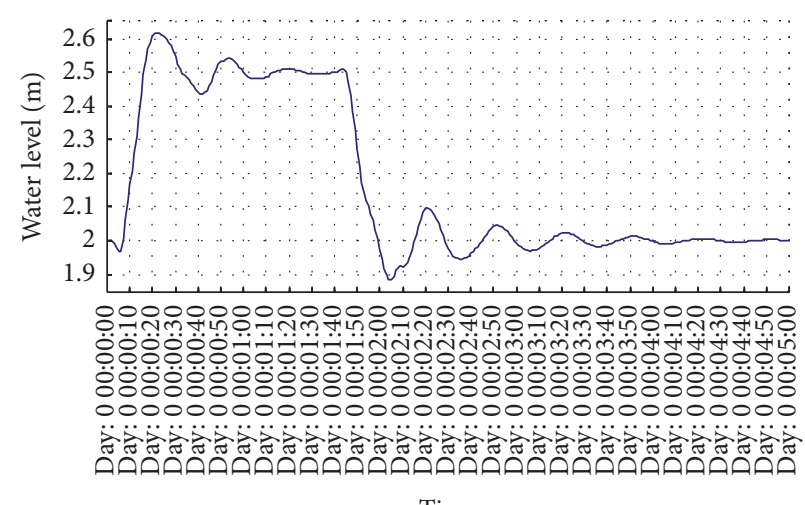

Time

(c) Water level at 3rd point

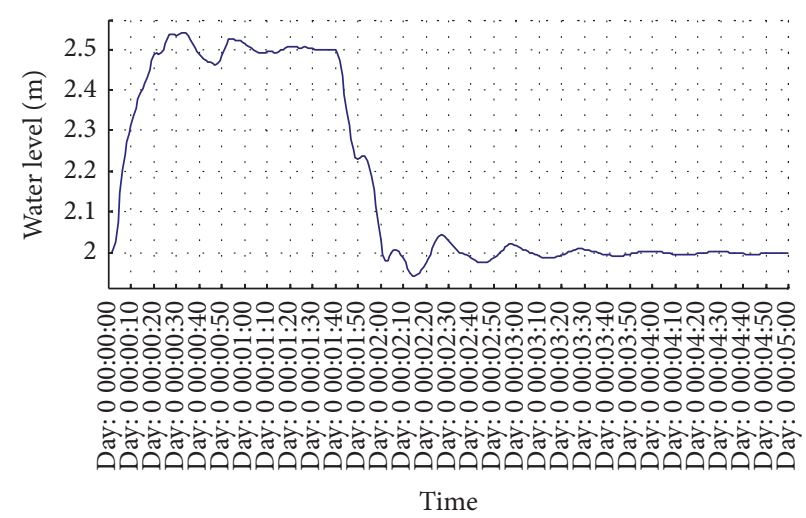

(b) Water level at 2nd point

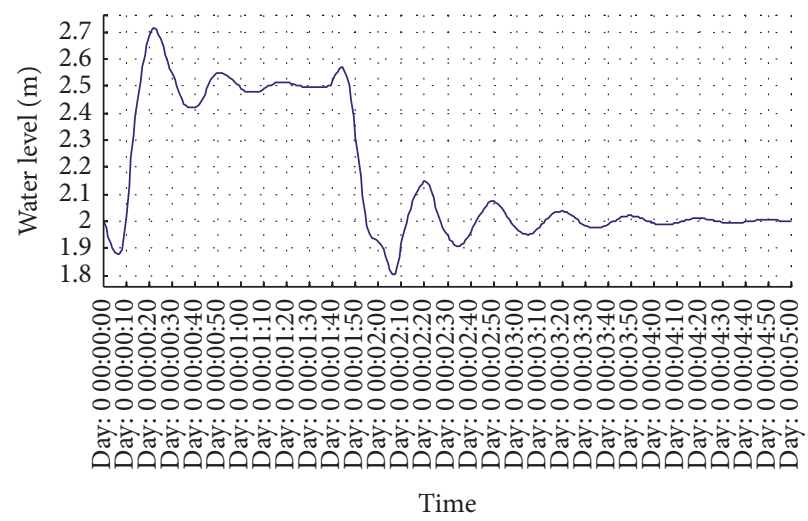

(d) Water level at 4th point

FIgURE 8: Evolutions of water levels at four points in pool 1 with $N=M=10$.

TABLE 1: Geometric parameters of one single-pool canal.

\begin{tabular}{lcccc}
\hline Length $(\mathrm{m})$ & Bottom width $(\mathrm{m})$ & Height $(\mathrm{m})$ & Bed slope & Side slope \\
\hline 1000 & 3.97 & 2.5 & 0.0005 & 0 \\
\hline
\end{tabular}

TABLE 2: Hydraulic conditions of one single-pool canal.

\begin{tabular}{lccc}
\hline$H_{u}(\mathrm{~m})$ & $H_{d}(\mathrm{~m})$ & Initial discharge $\left(\mathrm{m}^{3} / \mathrm{s}\right)$ & Initial water level $(\mathrm{m})$ \\
\hline 2 & 0.5 & 1 & 0.8 \\
\hline
\end{tabular}

TABLE 3: Geometric parameters of each pool of the cascaded canal.

\begin{tabular}{lcccc}
\hline Length $(\mathrm{m})$ & Bottom width $(\mathrm{m})$ & Height $(\mathrm{m})$ & Bed slope & Side slope \\
\hline 40 & 2 & 5 & 0 & 0.1 \\
\hline
\end{tabular}

TABLE 4: Hydraulic conditions of each pool of the cascaded canal.

\begin{tabular}{lcccc}
\hline$H_{u}(\mathrm{~m})$ & $H_{d}(\mathrm{~m})$ & Initial discharge $\left(\mathrm{m}^{3} / \mathrm{s}\right)$ & Initial water level in pool 1 $(\mathrm{m})$ & Initial water level in pool 2 $(\mathrm{m})$ \\
\hline 3.5 & 1.2 & 1 & 2 & 1.5 \\
\hline
\end{tabular}

Figures 8 and 9. From these figures, it is observed the water levels at four points are stabilized at the target values. The evolutions of three gate opening heights are illustrated in Figure 10.
In order to show the effects of MPC parameters on the control performance, two more scenarios with longer control horizon and prediction horizon are selected; that is, $N=$ $M=30$ and $N=M=60$. The simulation results run by 


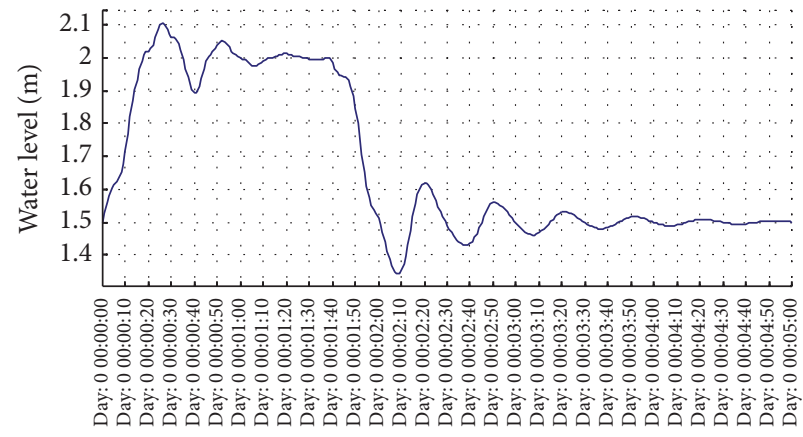

Time

(a) Water level at 1st point

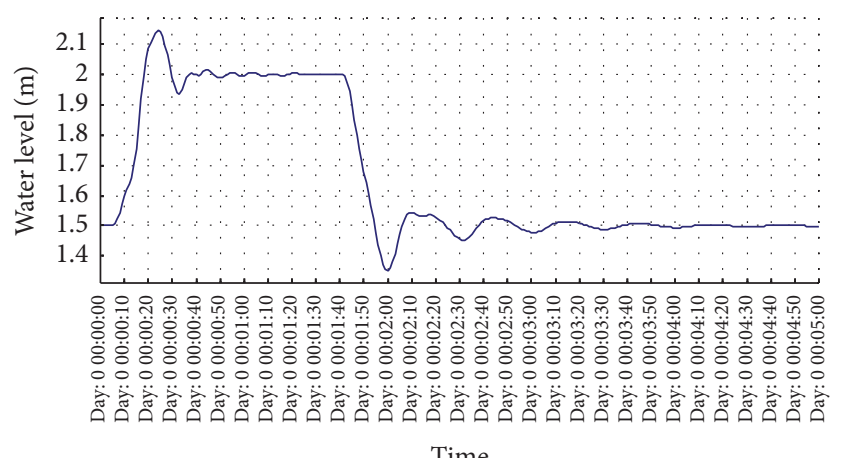

(c) Water level at 3rd point

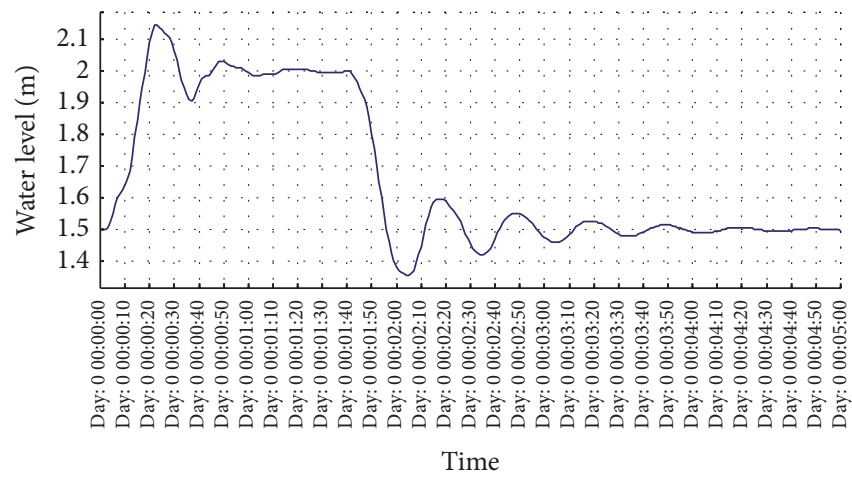

(b) Water level at 2nd point

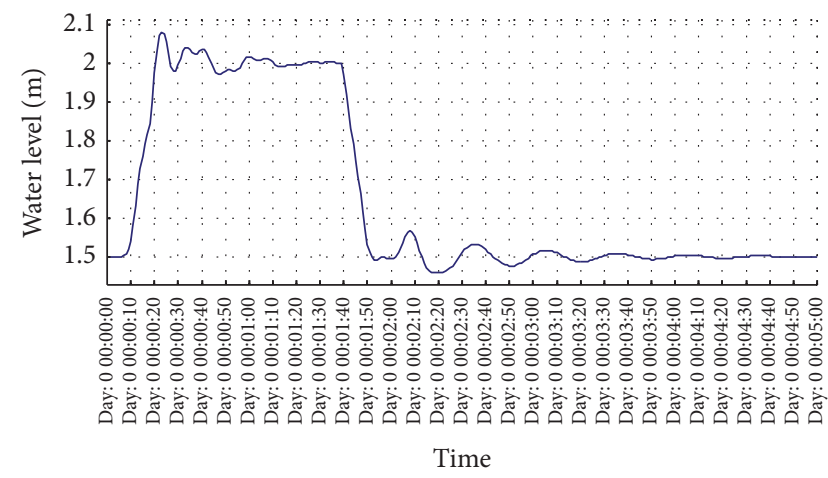

(d) Water level at 4th point

FIgURE 9: Evolutions of water levels at four points in pool 2 with $N=M=10$.

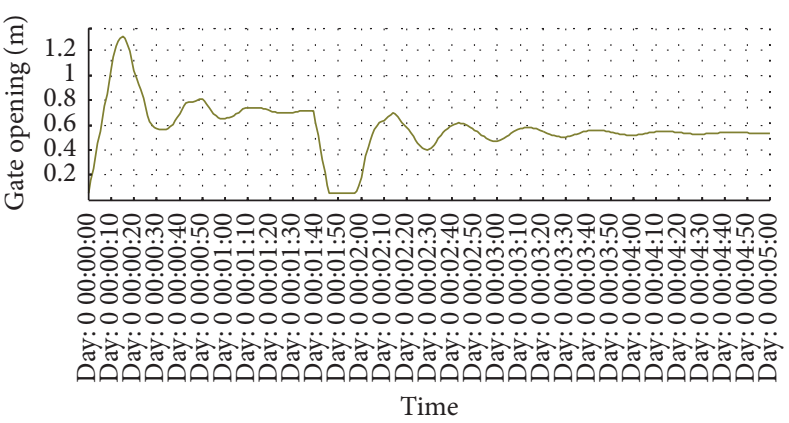

(a) Opening height of Gate 1

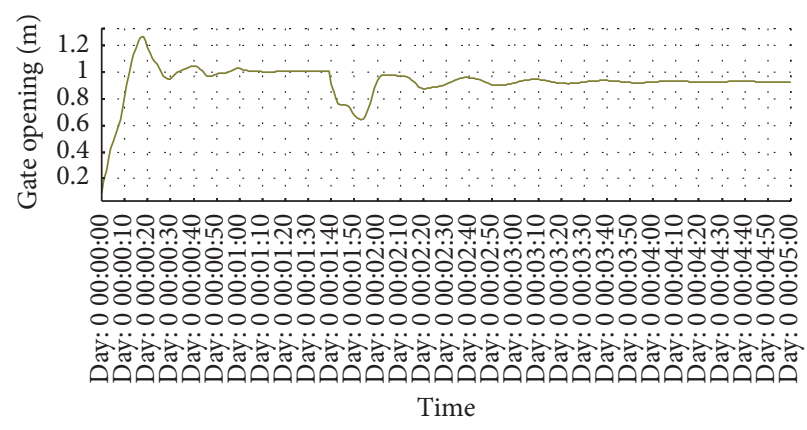

(b) Opening height of Gate 2

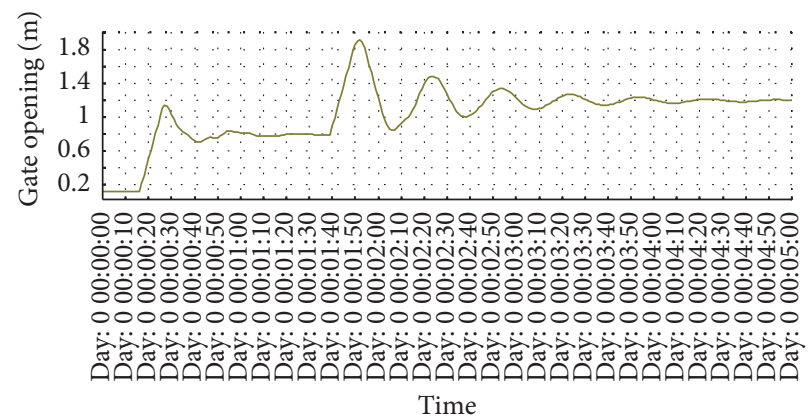

(c) Opening height of Gate 3

Figure 10: Evolutions of three gate opening heights with $N=M=10$. 


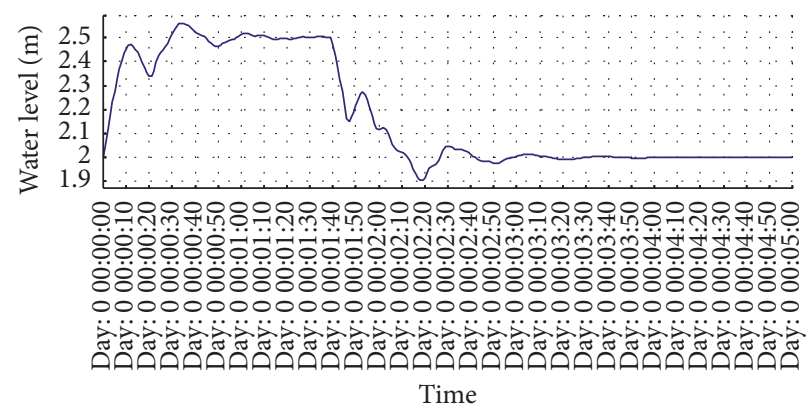

(a) Water level at 1st point

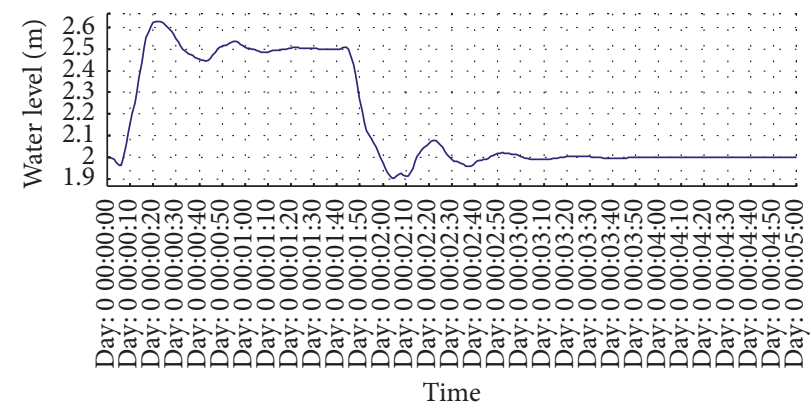

(c) Water level at 3rd point

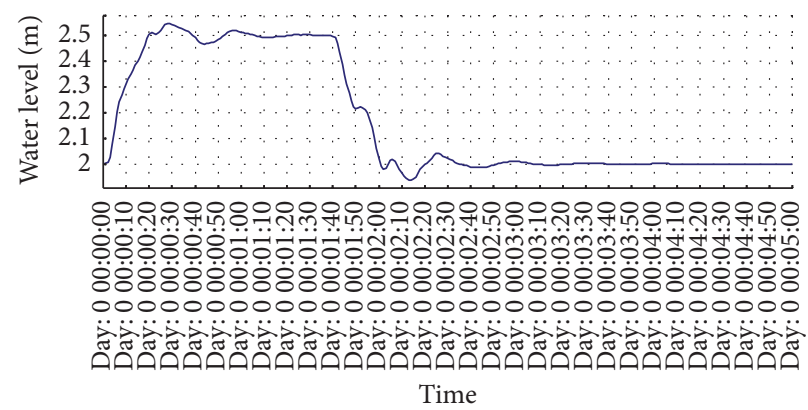

(b) Water level at 2nd point

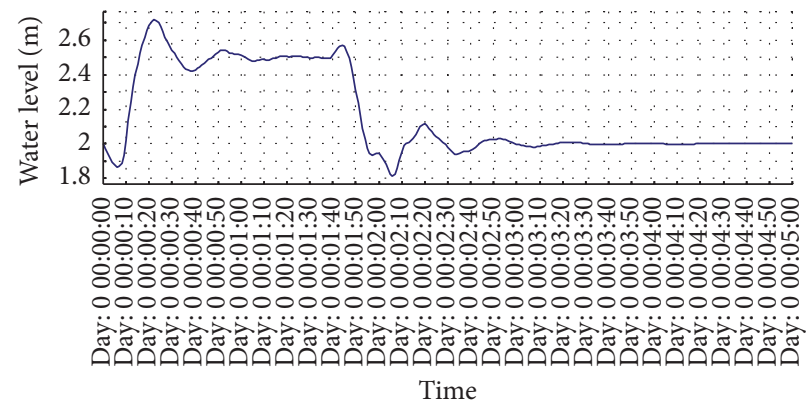

(d) Water level at 4 th point

FIGURE 11: Evolutions of water levels at four points in pool 1 with $N=M=60$.

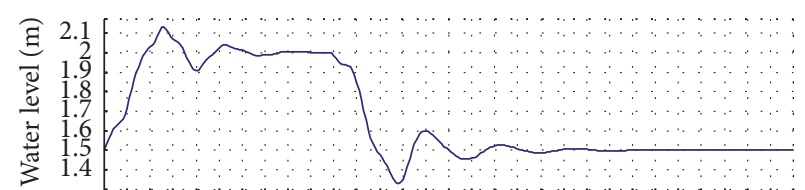

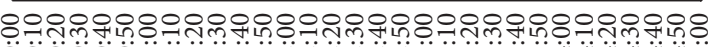
केँ்

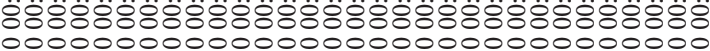

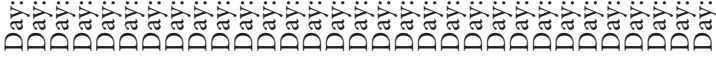

Time

(a) Water level at 1st point

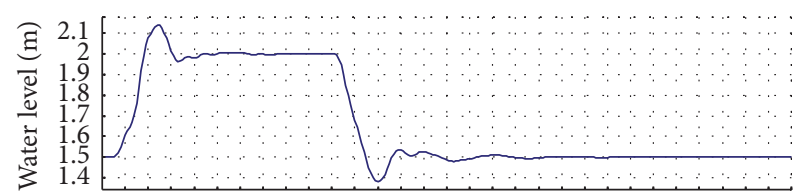

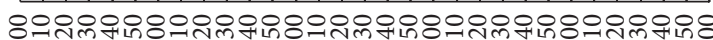

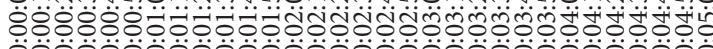
ठ்ல்ப்ப்

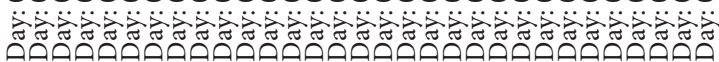
Time

(c) Water level at 3rd point

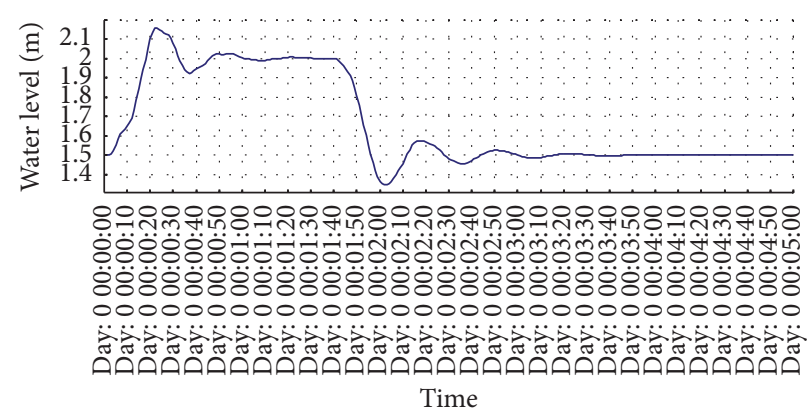

(b) Water level at 2nd point

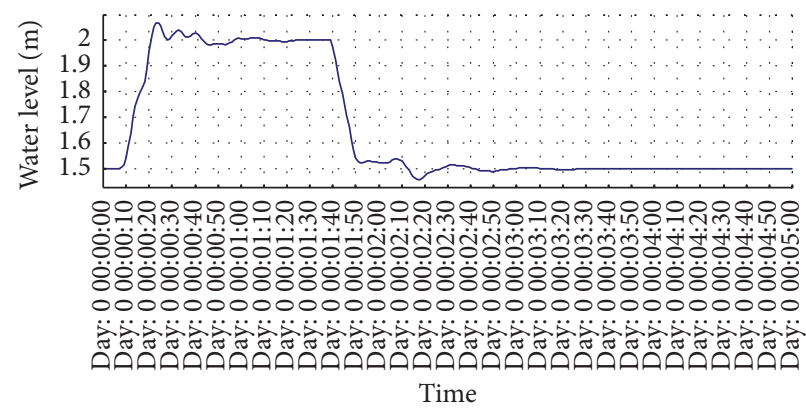

(d) Water level at 4 th point

FIGURE 12: Evolutions of water levels at four points in pool 2 with $N=M=60$.

SICC about the evolutions of the water level at each spatial point in two pools and the three gate opening heights are very similar to those of the first scenario with $N=M=10$. But longer control horizon and prediction horizon lead to faster stabilization to the target values. For the sake of simplicity, only the scenario with $N=M=60$ is shown in Figures 11, 12 , and 13 .

The control results, including the values of the performance index $J$ and the computational time, are summarized in Table 5. From the comparison, it is shown that longer 


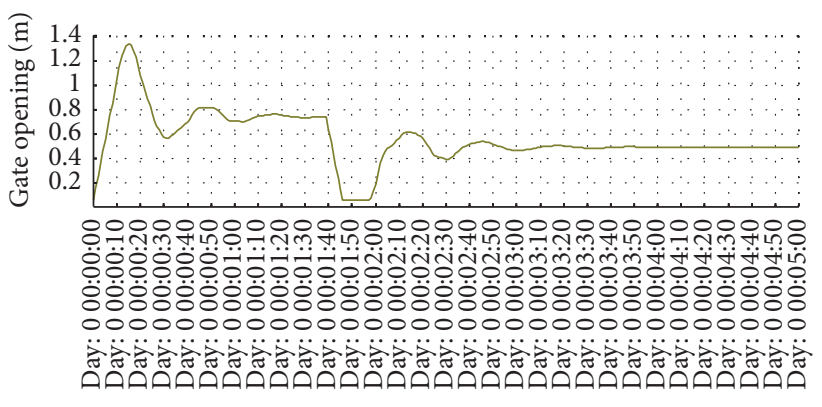

Time

(a) Opening height of Gate 1

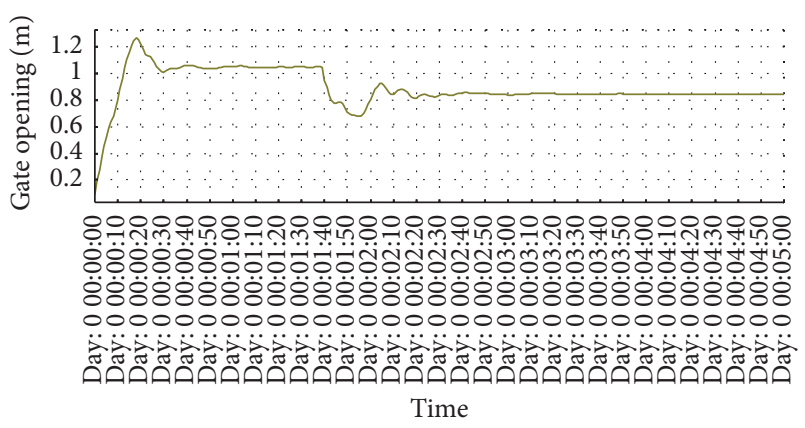

(b) Opening height of Gate 2

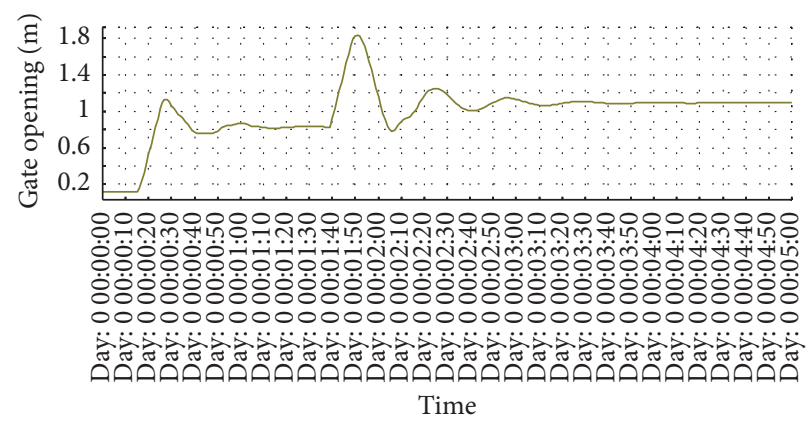

(c) Opening height of Gate 3

FIGURE 13: Evolutions of three gate opening heights with $N=M=60$.

TABLE 5: Comparisons of optimization performances and computational times.

\begin{tabular}{lccc}
\hline & $N=M=10$ & $N=M=30$ & $N=M=60$ \\
\hline$J$ & 39.811 & 38.887 & 38.864 \\
Run time (s) & 11.878 & 22.610 & 55.700 \\
\hline
\end{tabular}

control and prediction horizon result in better optimization performance and higher run time.

\section{Conclusions}

A predictive model of irrigation canals is mathematically derived from the Saint-Venant equations by discretization in both space and time. Since the gate control actions are restricted by the boundary water levels, a constrained model predictive control is developed for both a single-pool canal and multipool cascaded canal. The control performance of the proposed predictive control scheme is tested on one single-pool canal that is part of Yehe irrigation area in Hebei province of China and generalized to a two-pool cascaded canal. All the simulations carried out in SICC and MATLAB show that the constrained model predictive control could stabilize the water levels to the target values by regulating the gate opening heights. A performance comparison showed the control effects of different control horizon and prediction horizon. It should be emphasized that the predictive control is a centralized one. The time delays at the downstream points of each pool are caused due to the long conveying pool. A decentralized predictive control scheme could be a future work.

\section{Competing Interests}

The authors declare that they have no competing interests.

\section{Acknowledgments}

This work was supported by National Natural Science Foundation of China (NSFC) under Grant nos. 61473317, 61374156, and 61590921.

\section{References}

[1] J. de Halleux, C. Prieur, J.-M. Coron, B. Andrea-Novel, and G. Bastin, "Boundary feedback control in networks of open channels," Automatica, vol. 39, no. 8, pp. 1365-1376, 2003.

[2] L. Cen, Y. Xi, D. Li, and Y. Cen, "Boundary feedback control of open canals with a Riemann invariants approach," Transactions of the Institute of Measurement and Control, vol. 37, no. 7, pp. 900-908, 2015.

[3] J.-M. Coron, B. d'Andrea-Nove, and G. Bastin, "A strict Lyapunov function for boundary control of hyperbolic systems of conservation laws," Institute of Electrical and Electronics Engineers. Transactions on Automatic Control, vol. 52, no. 1, pp. 2-11, 2007.

[4] L. H. Cen and Y. G. Xi, "Stability of boundary feedback control based on weighted Lyapunov function in networks of open channels," Acta Automatica Sinica. Zidonghua Xuebao, vol. 35, no. 1, pp. 97-102, 2009. 
[5] P.-O. Malaterre, D. C. Rogers, and J. Schuurmans, "Classification of canal control algorithms," Journal of Irrigation and Drainage Engineering, vol. 124, no. 1, pp. 3-10, 1998.

[6] P.-J. van Overloop, S. Weijs, and S. Dijkstra, "Multiple Model Predictive Control on a drainage canal system," Control Engineering Practice, vol. 16, no. 5, pp. 531-540, 2008.

[7] R. R. Negenborn, P.-J. van Overloop, T. Keviczky, and B. De Schutter, "Distributed model predictive control of irrigation canals," Networks and Heterogeneous Media, vol. 4, no. 2, pp. 359-380, 2009.

[8] R. Negenborn, P. van Overloop J, and B. De Schutter, "Coordinated distributed model predictive reach control of irrigation canals," in Proceedings of the European Control Conference (ECC '09), pp. 1420-1425, Budapest, Hungary, August 2009.

[9] A. Zafra-Cabeza, J. M. Maestre, M. A. Ridao, E. F. Camacho, and L. Sánchez, "A hierarchical distributed model predictive control approach to irrigation canals: a risk mitigation perspective," Journal of Process Control, vol. 21, no. 5, pp. 787-799, 2011.

[10] A. Álvarez, M. A. Ridao, D. R. Ramirez, and L. Sánchez, "Constrained predictive control of an irrigation canal," Journal of Irrigation and Drainage Engineering, vol. 139, no. 10, pp. 841854, 2013.

[11] D. Georges, "Infinite-dimensional nonlinear predictive control design for open-channel hydraulic systems," Networks and Heterogeneous Media, vol. 4, no. 2, pp. 267-285, 2009.

[12] K. Horvath, P. J. van Overloop, E. Galvis, M. Gomez, and J. Rodellar, "Multivariable model predictive control of water levels on a laboratory canal," in Advances in Hydroinformatics, pp. 7792, 2014.

[13] V. T. Chow, Open Channel Hydraulics, Mac-Graw Hill Book Company, New York, NY, USA, 1985.

[14] Y. Zou, L. Cen, D. Li, and X. He, "Simplified state-space model and validation of irrigation canal systems," in Proceedings of the 34th Chinese Control Conference (CCC '15), pp. 2002-2007, IEEE, Hangzhou, China, July 2015.

[15] X. Ruan, Study on modeling and automatic control of open canals [Ph.D. thesis], Wuhan University, 2002.

[16] Z. W. Wu, L. Cen, S. Zhang, X. Chen, and S. Lin, "Optimal control of irrigation canals based on control vector parametrization," in Proceedings of the 35th Chinese Control Conference (CCC '16), pp. 2596-2601, Chengdu, China, July 2016.

[17] P. O. Malaterre and J. P. Baume, "SIC 3.0, a simulation model for canal automation design," in Proceedings of the International Workshop on the Regulation of Irrigation Canals: State of the Art of Research and Applications (RIC '97), vol. 1, pp. 68-75, Marrakesh, Morocco, 1997. 


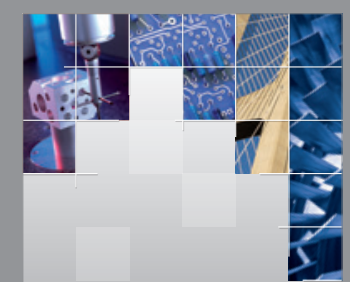

\section{Enfincering}
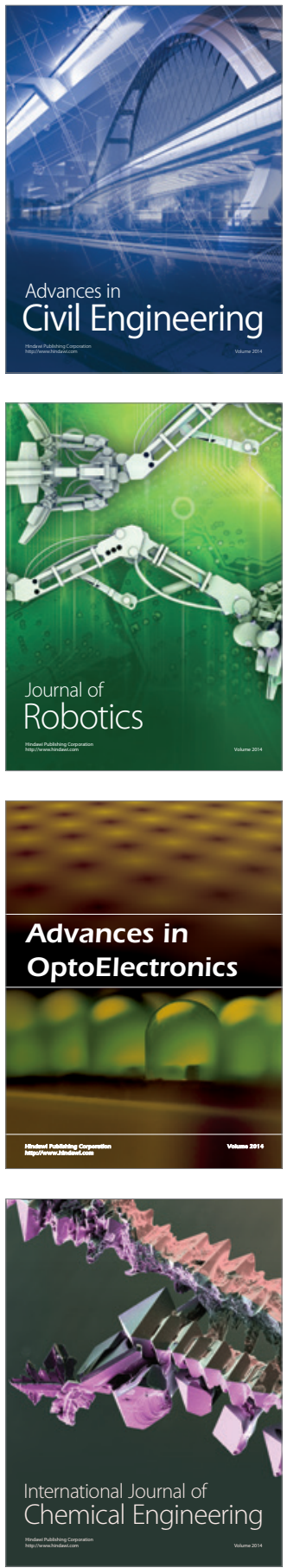

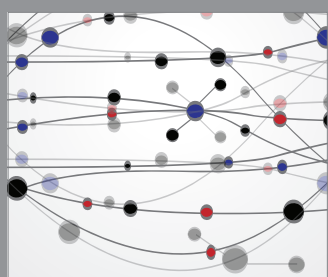

The Scientific World Journal

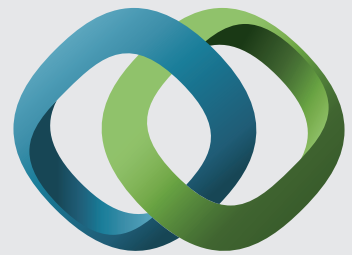

\section{Hindawi}

Submit your manuscripts at

https://www.hindawi.com
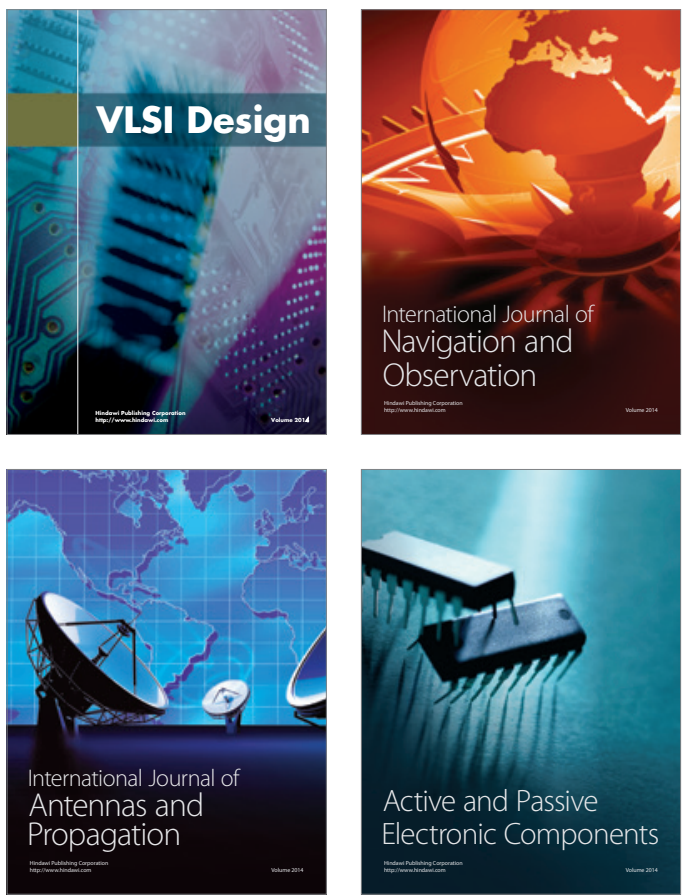
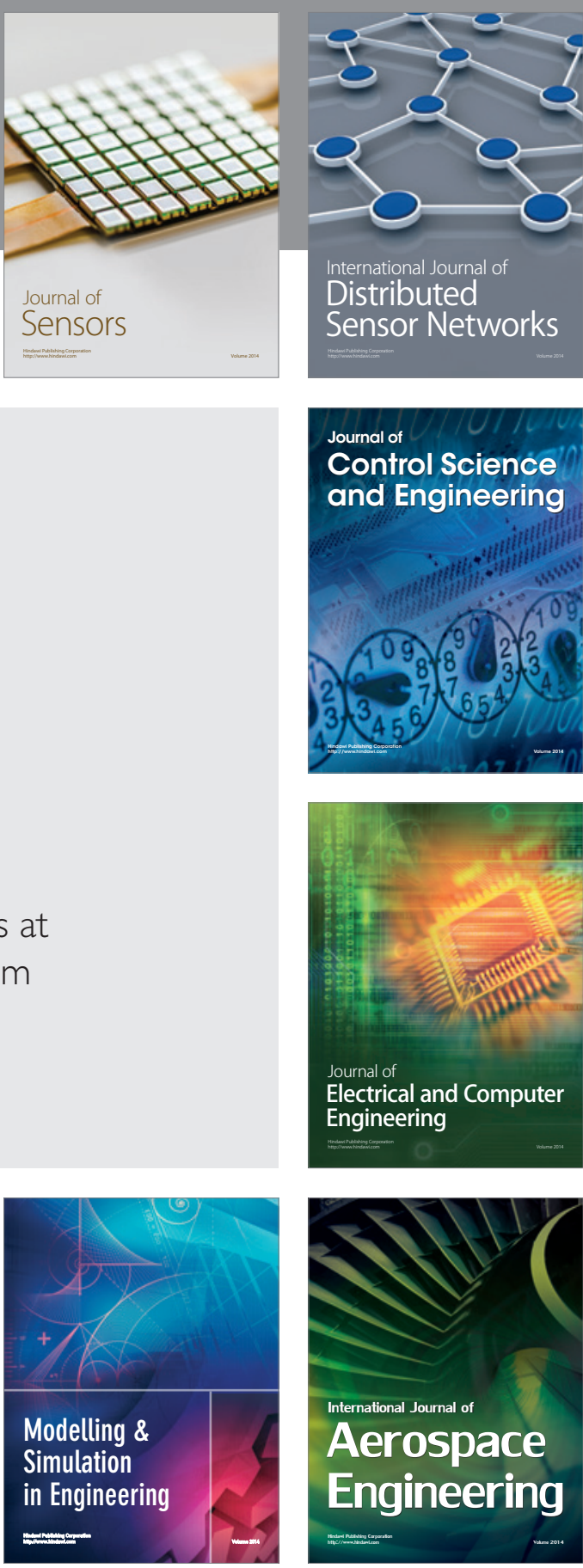

International Journal of

Distributed

Sensor Networks

$-$

Joumal of

Control Science

and Engineering
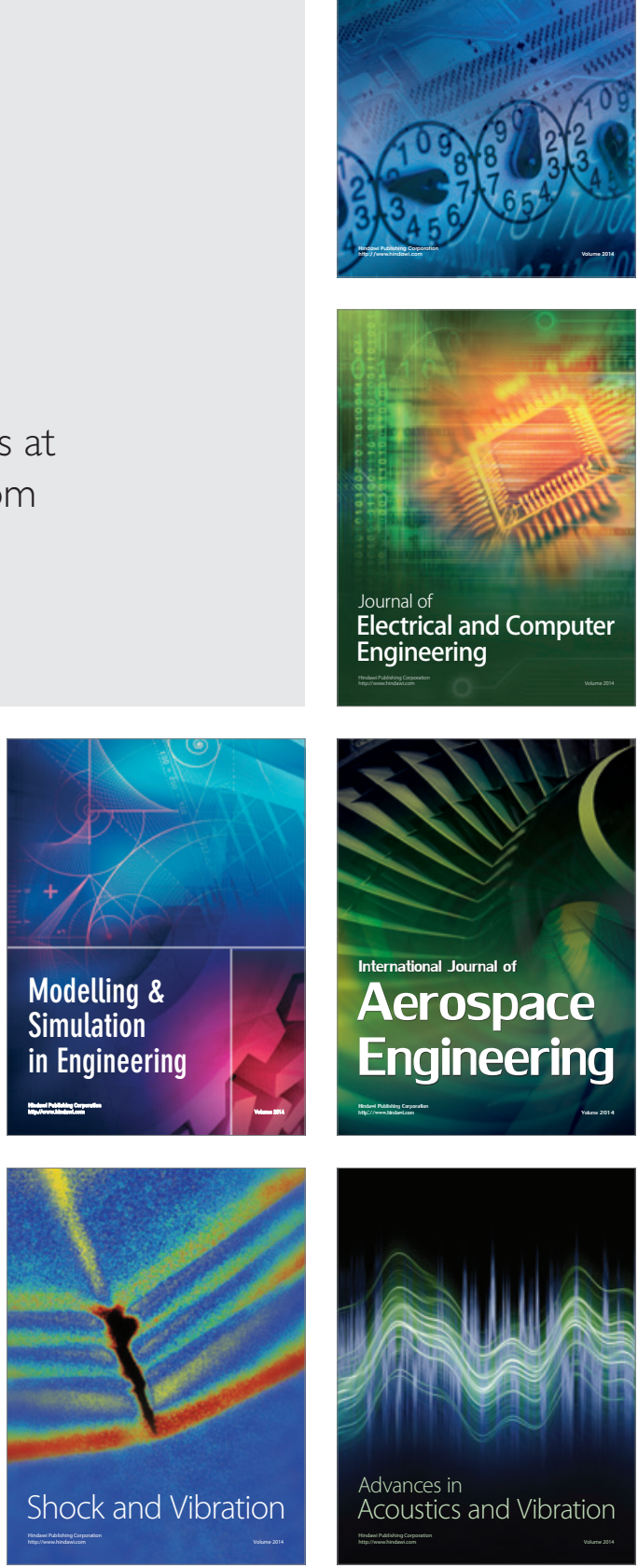